\title{
Measuring the Facebook Advertising Ecosystem
}

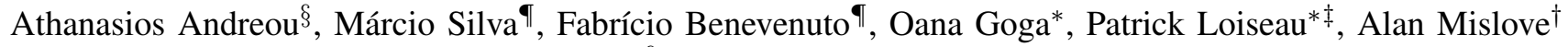 \\ $\S$ EURECOM, France \\ \{andreou\}@eurecom.fr \\ †Northeastern University, USA \\ \{amislove@ccs.neu.edu\} \\ IFederal University of Minas Gerais, Brazil \\ \{marcio@facom.ufms, fabricio@dcc.ufmg\}.br \\ *Univ. Grenoble Alpes, CNRS, Inria, Grenoble INP, LIG, France \\ \{oana.goga, patrick.loiseau\}@univ-grenoble-alpes.fr \\ $\ddagger$ Max Planck Institute for Software Systems (MPI-SWS), Germany
}

\begin{abstract}
The Facebook advertising platform has been subject to a number of controversies in the past years regarding privacy violations, lack of transparency, as well as its capacity to be used by dishonest actors for discrimination or propaganda. In this study, we aim to provide a better understanding of the Facebook advertising ecosystem, focusing on how it is being used by advertisers. We first analyze the set of advertisers and then investigate how those advertisers are targeting users and customizing ads via the platform. Our analysis is based on the data we collected from over 600 real-world users via a browser extension that collects the ads our users receive when they browse their Facebook timeline, as well as the explanations for why users received these ads.
\end{abstract}

Our results reveal that users are targeted by a wide range of advertisers (e.g., from popular to niche advertisers); that a nonnegligible fraction of advertisers are part of potentially sensitive categories such as news and politics, health or religion; that a significant number of advertisers employ targeting strategies that could be either invasive or opaque; and that many advertisers use a variety of targeting parameters and ad texts. Overall, our work emphasizes the need for better mechanisms to audit ads and advertisers in social media and provides an overview of the platform usage that can help move towards such mechanisms.

\section{INTRODUCTION}

The Facebook advertising platform has been the source of a number of controversies in recent years regarding privacy violations [31], [40], lack of transparency on how it provides information to users about the ads they see [22], and lately, Facebook's ability to be used by dishonest actors for discriminatory advertising [9], [16], [38] or ad-driven propaganda to influence elections [19]. For example, Propublica demonstrated how Facebook allowed advertisers to reach users associated with the topic of 'Jew Haters' [9], and also allowed advertisers to exclude people from ads about employment based on their age [16].

This situation has led many governments and privacy advocates to push Facebook to make its platform more transparent

Network and Distributed Systems Security (NDSS) Symposium 2019 24-27 February 2019, San Diego, CA, USA ISBN 1-891562-55-X

https://dx.doi.org/10.14722/ndss.2019.23280

www.ndss-symposium.org and more accountable for the ads that circulate on it [13]. However, providing transparency can be tricky for such a complex system. For example, Andreou et al. [22] recently showed that current transparency mechanisms provided by Facebook that explain why a user has received a particular ad are incomplete and sometimes misleading. In addition, a new report from Upturn [17] (supported by many privacy advocates) argued that Facebook's ad transparency efforts are far from sufficient:

Facebook's ad transparency tools do not include an effective way for the public to make sense of the millions of ads running on its platform at any given time ... [We recommend to] provide a strong baseline of access to all ads, not just those identified as political in nature ... [and] disclose data about ads' reach, type, and audience-especially for ads that implicate important rights and public policies.

So, despite Facebook's efforts to provide transparency, little is known about the ads inside the platform and how the various targeting features of the platform are used by advertisers.

There exist two primary characteristics of Facebook's advertising platform that make transparency both more crucial and more complex at the same time. First, every user with a Facebook account can become an advertiser in a matter of minutes with five clicks on Facebook's website; there is no verification required to become an advertiser, and no need to provide an identity card or proof of a legitimate registered business. Second, the platform provides advertisers with a wide range of ways to target users. For example, advertisers are able to target users that satisfy precise combinations of attributes - based on a list of over 200,000 attributes provided by Facebook-resulting in complex targeting formulas such as "interested in tennis and having very liberal convictions but not living in ZIP code 02115" [5]. Alternatively, advertisers can target specific users if they know information such as the user's email address or phone number (referred to as Personally Identifiable Information or PII; see Section II for more details). We do not aim to debate whether such targeting strategies should be allowed in the first place, but we do believe that in order to design better transparency mechanisms, it is necessary to have an understanding of how they are being used by advertisers. 
In this paper, we provide a detailed look at how the Facebook advertising ecosystem is being used. To do so, we first study Who are the advertisers? (Section IV) and then How are the advertisers using the platform? (Section V). We investigate topics such as the most common targeting strategies advertisers use, the users who advertisers target the most, and how advertisers tailor their ads to specific users. To do so, we analyze data from 622 real-world Facebook users, based on two versions of AdAnalyst [4]. In brief, AdAnalyst is a browser extension that we developed to collect the ads users receive when they browse their Facebook timeline, as well as the corresponding explanations Facebook provides about the reasons they have been targeted with each particular ad. In total, we analyze data about $89 \mathrm{~K} / 146 \mathrm{~K}$ ads and $22 \mathrm{~K} / 28 \mathrm{~K}$ advertisers (see Section III). While our data is unique and provides a new perspective on the Facebook advertising ecosystem, it does have biases due to the way we disseminate AdAnalyst, and limitations due to the incompleteness of ad explanations provided by Facebook. We provide precise descriptions of how these limitations impact the results and findings throughout the paper.

Our work is the first study of ads and advertisers in Facebook at a moderate scale. While there have been many studies about online ad targeting [25], [27], [30], [33]-[36], [42], none focused extensively on social media advertising on Facebook. This is important because Facebook has the highest ad volume amongst social media platforms and it offers a wider range of data and targeting mechanisms than traditional advertising. Facebook is also often a pioneer in introducing new targeting mechanisms such as PII-based targeting (see Section III). Additionally, our study differs from previous works in several other ways. First, we analyze the ad targeting strategies of a large number of advertisers on Facebook. Related work on Facebook [22] has focused on explanations of ad targeting, but it only performed controlled experiments to evaluate the transparency mechanisms Facebook provides. We use their results as a basis to interpret the large-scale datasets of ads and explanations we collect. Second, we analyze ads collected from real-world users in contrast to the more traditional techniques for collecting ads by creating fake personas and visiting a predefined set of websites to collect the corresponding ads [25]. We believe our study offers a unique view of the Facebook advertising ecosystem that will be very useful for subsequent efforts to increase its transparency.

Our analysis in Section IV of the set of advertisers on Facebook reveals that the ecosystem is broad and complex. There exist advertisers that are well-known and popular (i.e., having more than $100 \mathrm{~K}$ Likes, covering $32 \%$ of all advertisers) amongst which over $73 \%$ have a verified account. At the same time, there exist many advertisers that are niche (i.e., have less than $1 \mathrm{~K}$ Likes, covering $16 \%$ of all advertisers) and whose trustworthiness is difficult to manually/visually assess (e.g., less than $7 \%$ of them are verified). We also see that a non-negligible fraction of advertisers are part of potentially sensitive categories such as News and Politics, Education, Business and Finance, Medical, Legal and Religion.

Our analysis in Section $\mathrm{V}$ of how the advertisers are using the platform reveals that:

(1) Targeting strategies advertisers use: A significant fraction of targeting strategies (20\%) are either potentially invasive (e.g., make use of PII or attributes from third-party data brokers to target users), or are opaque (e.g., use the Lookalike audiences feature that lets Facebook decide to whom to send the ad based on a proprietary algorithm). This represents a shift from more traditional targeting strategies based on location, behavior, or re-targeting. Finally, most advertisers (65\%) target users with one single ad, and only a small fraction (3\%) target users persistently over long periods of time.

(2) Users who advertisers target: A significant fraction of advertisers (24\%) use multiple attributes to target users, with some using as many as 105 attributes! While in most cases the targeting attributes are in accordance with the business domain of the advertiser, we do find cases of questionable targeting even from large companies, which emphasizes the need for more visibility and accountability in what type of users advertisers target.

(3) How advertisers tailor their ads: A surprisingly large number of advertisers change the content of their ads either across users $(79 \% 1)$, across targeting attributes $(65 \% 1)$, or across time (86\%). While this practice is not inherently malicious, it requires close monitoring as it could open the door to manipulation via micro-targeting.

Overall, our analysis points to the fact that users receive ads that often come from potentially sensitive advertiser categories, that are targeted using invasive strategies, and whose quality is difficult to assess. Our work emphasizes the need for better mechanisms to audit ads and advertisers, to increase transparency, and to protect users from dishonest practices. In particular, we find a significant fraction of Lookalike audience targeting, for which current transparency mechanisms are unsatisfactory; our work therefore points to the necessity of finding appropriate transparency mechanisms for this targeting. Similarly, we find that $79 \%$ of users have received an ad using PII-based targeting, pointing to the need to find ways of better explaining how advertisers received this information in the first place [41]. We also find that many advertisers run multiple campaigns with various targeting strategies and/or various ads; this points to the necessity of adopting a global approach towards transparency that does not look at ads in isolation.

As a step forward, our AdAnalyst browser extension provides users with aggregate statistics about who are the advertisers that target them, and what are the properties of other users that were targeted by the same advertisers, which we hope will help users protect themselves from dishonest practices and gain a better understanding of the ads they receive. The AdAnalyst extension can be downloaded and run from the URL below:

$$
\text { https://adanalyst.mpi-sws.org }
$$

\section{BACKGROUND}

In this section we take a quick look at how one can advertise on Facebook and the transparency mechanisms Facebook provides to users.

\footnotetext{
${ }^{1}$ Out of the relevant set of advertisers.
} 


\section{A. Advertising in Facebook}

Becoming a Facebook advertiser is a simple process: to sign up, one only needs a (personal) Facebook account and a payment method (e.g., a credit card). In a few clicks, any user can become an advertiser by simply clicking on "Create Ads" from dropdown menu. To place an ad, advertisers need to create a targeting audience where they specify the users they want to target, choose some optimization criteria, upload their ad's text and image, and place a bid [3].

To create a targeting audience, Facebook provides prospective advertisers with a plethora of options. First, advertisers can target users based on their age, gender, location, and the language they speak. Second, advertisers can target users based on combinations of attributes representing the characteristics they want users who receive their ads to have (e.g. users interested in both table tennis and pizza). Targeting attributes are grouped into high-level categories of demographics, behaviors, and interests [22]. Interests can either be predefined (where the advertisers can browse in a tree structure of attributes in order to target users) or free-text (where the advertisers can type something they believe is related with their desired targeting and browse to related attributes).

Third, advertisers can target users via Custom audiences, where the advertiser selects specific users. Advertisers can do so by uploading a list of various types of personally identifiable information (PII), including email addresses, phone numbers, physical addresses, names, and dates of birth. They can also create Custom audiences by selecting users who have visited their third-party website, installed their mobile application, or 'Liked' their Facebook Page. Fourth, advertisers can target users via Lookalike audiences. In brief, advertisers can start with a Custom audience and ask Facebook to identify other Facebook users who are similar to ('lookalike') users in the source audience. Facebook does not precisely define how it measures similarity, or disclose its algorithm for selecting users.

Advertisers can also combine different targeting options together, such as first targeting using a Custom audience and then further targeting using age, gender and targeting attributes [14].

\section{B. Facebook's transparency mechanisms}

Facebook provides explanations to users about why they have received a specific ad, we call these ad explanations. To obtain such explanations users need to click on the "Why am I seeing this?" button that is in the upper right corner of every ad. Ad explanations are usually structured in two parts. The fist part reveals a part of the targeting and looks like:

One reason you're seeing this ad is that [advertiser] wants to reach people interested in [attribute], based on activity such as liking Pages or clicking on ads.

The second part of an explanation reveals attributes that might have been potentially used by an advertiser:

There may be other reasons you're seeing this ad, including that [advertiser] wants to reach people ages [age range] who live in [location]. This is information based on your Facebook profile and where you've connected to the internet.

These explanations provide insight into how a user was targeted. Prior work [22] demonstrated that some explanations are more informative than others, depending on the way a user was targeted (see more details in Section III-B).

Another transparency mechanism that Facebook offers is the Ad Preferences page [3]. There, users can see (some of) the attributes that Facebook has inferred about them [22].

\section{DATASET}

In this paper, we use a dataset collected with the help of AdAnalyst [4]. AdAnalyst is a browser extension available for Chrome and Firefox that collects three main types of information as users browse Facebook: (1) the ads users receive when they browse their Facebook timeline; (2) the ad explanations provided by Facebook on why they receive a particular ad, and (3) the Ad Preferences pages of the users. We deployed AdAnalyst in two different instances; one for broader worldwide audiences, and one with a focus on Brazilian users. The Brazilian instance was disseminated as part of a project ${ }^{2}$ to provide transparency about political campaigns in the 2018 Brazilian elections.

In this study, we look at data collected from both versions of AdAnalyst. We call the dataset obtained by the version for broader audiences DATA-WORLDWIDE, and the data obtained from the version focused on Brazilian users DATA-BRAZIL. When we do not mention results from DATA-BRAZIL or combined results explicitly, we will be referring to results from DATA-WORLDWIDE.

We only use data from users that installed AdAnalyst for more than one day. In total, we have 114 users in DATAWORLDWIDE and 508 in DATA-BRAZIL. DATA-WORLDWIDE includes data that have been collected over a period of one year and four months, while DATA-BRAZIL over a period of five months. The median number of days for which we have data for a user is 35 (29 in DATA-BRAZIL). Next, we provide more details about the data we collect and how we collect it.

\section{A. Data collection}

Ads: In order to capture the ads that users receive on Facebook, AdAnalyst inspects the DOM on Facebook pages for the tag "Sponsored". This tag is used by Facebook to help users distinguish sponsored content (i.e., ads) from the other posts in their Facebook feed. Ads appear either as Facebook posts (i.e., front ads), or appear on the right side of the screen (i.e., side $a d s)$. We capture the media content of the ad, the text of the ad, and the identity of the advertiser. AdAnalyst does not collect video ads that appear when a user is watching a video on Facebook. Ads are accompanied by an ad id, which we can use to identify unique ads. In total, we have collected $88.6 \mathrm{~K}$ unique ads in DATA-WORLDWIDE and $145.8 \mathrm{~K}$ in DATA-BRAZIL. The median number of unique ads received by a user daily is 11.1 (11.5 in DATA-BRAZIL).

\footnotetext{
${ }^{2}$ www.eleicoes-sem-fake.dcc.ufmg.br
} 
TABLE I. GEOGRAPHICAL DISTRIBUTION OF THE DATASETS.

\begin{tabular}{l|crr|rrr} 
& \multicolumn{3}{|c|}{ WORLDWIDE } & \multicolumn{3}{c}{ BRAZIL } \\
Location & Users & Ads & Adv. & Users & Ads & Adv. \\
\hline Europe & 85 & $71 \mathrm{~K}$ & $19 \mathrm{~K}$ & 7 & $5 \mathrm{~K}$ & $2 \mathrm{~K}$ \\
South America & 1 & 296 & 130 & 495 & $137 \mathrm{~K}$ & $25 \mathrm{~K}$ \\
North America & 16 & $8 \mathrm{~K}$ & $2 \mathrm{~K}$ & 5 & $4 \mathrm{~K}$ & $2 \mathrm{~K}$ \\
Rest & 12 & $10 \mathrm{~K}$ & $2 \mathrm{~K}$ & 0 & 0 & 0 \\
\hline France & 50 & 23 & $8 \mathrm{~K}$ & 1 & 43 & 36 \\
Germany & 16 & $46 \mathrm{~K}$ & $12 \mathrm{~K}$ & 1 & $2 \mathrm{~K}$ & 785 \\
Brazil & 1 & 296 & 130 & 495 & $137 \mathrm{~K}$ & $25 \mathrm{~K}$ \\
United States & 16 & $8 \mathrm{~K}$ & $2 \mathrm{~K}$ & 3 & $3 \mathrm{~K}$ & $1 \mathrm{~K}$ \\
\hline \hline Total & 114 & $89 \mathrm{~K}$ & $22 \mathrm{~K}$ & 508 & $146 \mathrm{~K}$ & $28 \mathrm{~K}$
\end{tabular}

Ad explanations: By simulating the click on the "Why am I seeing this" button of each ad, AdAnalyst collects the explanation that the user can see regarding the respective ad. Facebook imposes very strict and opaque rate limits with respect to the maximum number of explanations we can retrieve. These rate limits present an accessibility obstacle to users, and consequently also to AdAnalyst. Thus, we developed a scheduling mechanism where we collect all the HTTP requests that can be used to retrieve explanations and get only 10 explanations per hour. Additionally, we do not collect an explanation for an ad if we have already collected the explanation for the same ad for the same user within the previous two days. Our methodology achieves the collection of explanations for most ads, but does not ensure the collection of every explanation. In total, we collected $84.2 \mathrm{~K}$ unique ads with their explanations (129.1K for DATA-BRAZIL). We did not manage to collect explanations for $4.4 \mathrm{~K}$ ads (16.7K for DATA-BRAZIL).

We parse these explanations to retrieve information on the types of targeting that were used, and the targeting attributes that are mentioned. For each targeting attribute, we also obtain its audience size (e.g., the number of Facebook users that satisfy the attribute) from the Facebook Advertising Interface [8].

Ad Preferences: For each user, AdAnalyst collects the information found in their respective Ad Preferences pages periodically. From there, we have collected information about all the attributes that Facebook has inferred about users. In total, we collected $17.1 \mathrm{~K}$ distinct interests, behaviors and demographics (38.2K for DATA-BRAZIL) from all users. The median number of attributes that Facebook has inferred for a user is 310 (615 for DATA-BRAZIL)

Advertisers: From all the ads we collected in our dataset, we extracted $22 \mathrm{~K}$ unique advertisers (28K for DATA-BRAZIL). In order to be able to advertise on Facebook, advertisers currently need to create a Facebook Page, while this was not the case in the past. In total, $99.4 \%$ of our advertisers have a Facebook Page (100\% for DATA-BRAZIL).

The Facebook Pages can provide information about advertisers. From these pages, we collect the categories that the advertiser belongs to, the number of people who have 'Liked' the Page, and the verification badge (i.e., if the advertiser is verified by Facebook).

\section{B. Data limitations}

There are two sources of biases and limitations in our dataset, one that comes from users that installed AdAnalyst
TABLE II. COMPARISON OF AGE, GENDER, BASIC EDUCATION DISTRIBUTION IN DATA-WORLDWIDE, DATA-BRAZIL AND FACEBOOK GLOBAL POPULATION.

\begin{tabular}{l|r|r|r} 
& & DATA- & DATA- \\
& Facebook & WORLDWIDE & BRAZIL \\
\hline $13-17$ & $6.9 \%$ & $0.0 \%$ & $1.8 \%$ \\
$18-21$ & $16.5 \%$ & $1.8 \%$ & $7.1 \%$ \\
$22-30$ & $32.5 \%$ & $47.4 \%$ & $38.0 \%$ \\
$31-40$ & $21.2 \%$ & $25.4 \%$ & $26.6 \%$ \\
$41-50$ & $11.3 \%$ & $7.0 \%$ & $6.9 \%$ \\
$51-60$ & $6.5 \%$ & $1.8 \%$ & $2.2 \%$ \\
$61-65+$ & $5.2 \%$ & $0.0 \%$ & $0.6 \%$ \\
Not inferred & $0.0 \%$ & $16.7 \%$ & $16.9 \%$ \\
\hline Men & $57.0 \%$ & $68.4 \%$ & $74.4 \%$ \\
Women & $43.0 \%$ & $25.4 \%$ & $19.3 \%$ \\
Not inferred & $0.0 \%$ & $6.1 \%$ & $6.3 \%$ \\
\hline No University & $14.8 \%$ & $2.6 \%$ & $7.7 \%$ \\
University & $35.9 \%$ & $71.1 \%$ & $73.4 \%$ \\
Unspecified & $49.3 \%$ & $26.3 \%$ & $18.9 \%$
\end{tabular}

and one that comes from the way Facebook provides ad explanations.

Representativeness and bias: Representativeness is an important but challenging issue in any empirical study such as ours. We designed a methodology to gather Facebook ads that is as thorough as possible, given our practical constraints. We used two different strategies to disseminate AdAnalyst. The first consisted of disseminating it in our social and family circles as well as in the conferences we attended. For this version, users had to set their Facebook language to English or French. The second dissemination strategy consisted of providing AdAnalyst as part of a system focused on bringing transparency to the Brazilian 2018 elections, in a version that also works in Portuguese. In order to inspect possible biases in our dataset, we leverage information that we can infer about the users in our dataset from their ad explanations (i.e., their age group, gender and location), and Ads Preferences page (i.e., their interest-, behavior- and demographic-based attributes), and compare them with the global Facebook population. To estimate the fraction of users in the global Facebook population with a certain demographic or interest we use the Facebook Ads Interface [8] and query for monthly active users that satisfy the respective criteria worldwide as well as in Brazil, Europe and North America ${ }^{3}$

The geographical distribution of our datasets across continents and some selected countries is depicted in Table I] We see that, while we do not cover the world representatively, we do observe some geographical diversity in particular thanks to the combination of the DATA-WORLDWIDE and the DATABRAZIL dataset. Table II compares the age, gender and education level of users in our datasets and the Facebook global population. We see that our dataset is biased towards: young ages, with $47.4 \%$ of the users being between $22-30$ years oldcompared to $32.5 \%$ in the Facebook global population ${ }^{4}$ men, with $68.4 \%$ of the users being male-compared to $57 \%$ in the Facebook global population; and educated users, $71.1 \%$

\footnotetext{
${ }^{3}$ In the query we optimize for reach and leave the default "automatic placements" option selected, which includes users in the whole Facebook network (e.g., Instagram, mobile users, messenger, and audience network).

${ }^{4}$ Given that we could not infer the age group for $16.7 \%$ of our users.
} 


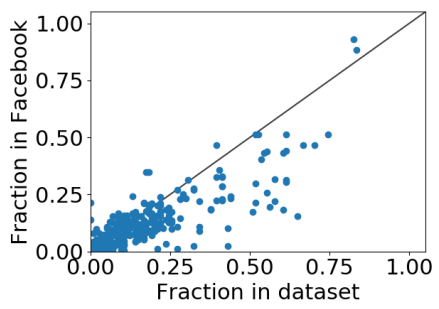

(a) DATA-WORLDWIDE.

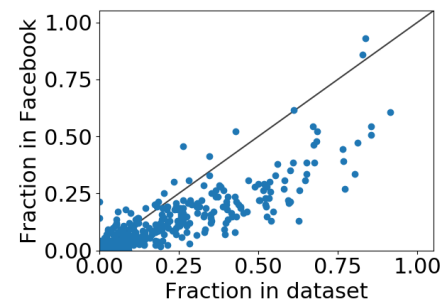

(b) DATA-BRAZIL.
Fig. 1. Scatterplot for the distribution of attributes for DATA-WORLDWIDE and Facebook's worldwide population, and DATA-BRAZIL (only brazilian users) and Facebook's Brazilian population.

of users have indicated tertiary education in their profilecompared to $35.9 \%$ in the Facebook global population. Overall, we observe that the biases seem closely related to our dissemination strategies and often transcend geographical boundaries.

We then investigate the biases in our dataset by looking at the fraction of users in our datasets for which Facebook has inferred an attribute and compare it with the fraction in the Facebook population. Figure 1 presents the comparison for 451 predefined attributes ${ }^{5}$ comparing all users in DATA-WORLDWIDE with the Facebook's population worldwide and the 495 Brazilian users from DATA-BRAZIL with the Facebook's population in Brazil. The scatter plot shows that there is a correlation between the representation of most attributes in the Facebook population and in our datasets (worldwide population vs. DATA-WORLDWIDE and Brazilian population vs. DATA-BRAZIL) with the Pearson's correlation coefficient being 0.86 for DATA-WORLDWIDE and 0.87 for DATA-BRAZIL. We also see that many attributes seem to be over-represented in our dataset, especially in the case of DATABRAZIL. This is probably due to the fact that users in our datasets have, on average, more attributes than Facebook users in general. Our estimated average number of attributes (out of those examined) per user in Facebook worldwide is 40 (44 in Brazil), while the average number of attributes per user in DATA-WORLDWIDE is 54, and in DATA-BRAZIL is 75.

To investigate in which aspects our dataset is most biased, Table III shows for each selected geographical region the attributes that have the biggest absolute difference in representation between our datasets and Facebook's population in these regions. We observe that users in Europe, and North America, which belong to DATA-WORLDWIDE, are far more likely to be Frequent Travelers, Frequent international travelers or Close friends of expats than the general Facebook population in these regions. DATA-BRAZIL is more biased towards attributes that might be hinting towards more affluent and educated individuals (e.g., People who prefer high-value goods in Brazil, Science, Books, and Engineering).

Overall, we believe that we collected a sufficient amount of ads from a sufficient amount of advertisers to draw valuable conclusions. In addition, the geographical diversity of our

\footnotetext{
${ }^{5}$ We use all Facebook predefined attributes that are leaves in the Facebook attribute hierarchy, do not have a time duration smaller than 6 months (e.g., Newlywed (3 months)), and cannot be used by advertisers to exclude audiences.
}

TABLE III. ATTRIBUTES WHOSE FREQUENCY IN OUR DATASET (D) PER REGION DIFFERS THE MOST FROM THE RESPECTIVE FACEBOOK'S ATTRIBUTE FREQUENCY (F).

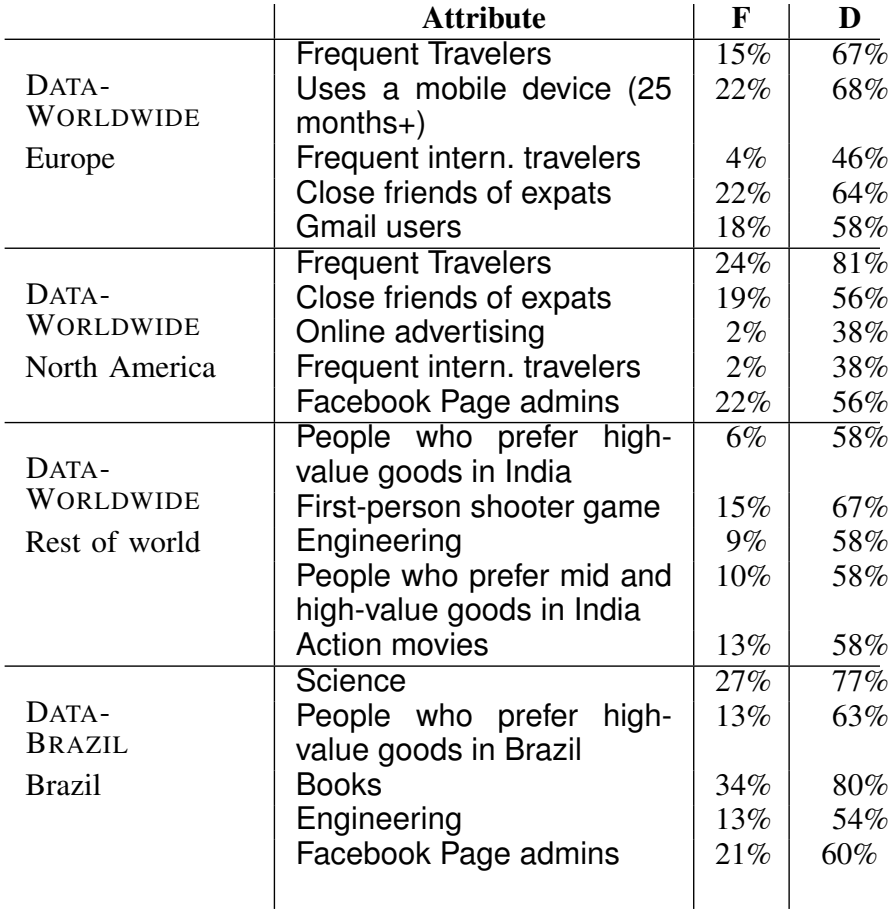

data allows us to assess the extent to which some of our observations are robust across regions.

Limitations on ad explanations: Andreou et al. [22] showed that ad explanations are incomplete: each explanation shows at most one targeting attribute (plus age/gender/location information) regardless of how many attributes the advertisers use. This means that explanations reveal only part of the targeting attributes that were used, providing us — and the users - with an incomplete picture of the attributes that advertisers were using. However, in the same study, authors performed a number of controlled experiments that suggest—but not conclusively prove-that there is a logic behind which attributes appear in an explanation and which do not. Given a targeting audience $A$ obtained from two attributes $a_{1} \wedge a_{2}$, if $a_{1}$ and $a_{2}$ come from different high-level attribute categories (e.g., Demographic, Behavior, or Interest), the attribute shown follows a specific precedence (Demographics or Age/Gender/Location $>$ Interests $>$ PII-based $>$ Behaviors). If $a_{1}$ and $a_{2}$ come from the same attribute category, the one that appears in the explanation is the one with the highest estimated audience size. These observations allow us estimate whether our results about a specific targeting type are underestimated or not. We will detail how this limitation impacts the results throughout the paper.

TABLE V. FRACTIONS OF ADVERTISERS THAT ARE VERIFIED (BLUE = BLUE BADGE, GRAY = GRAY BADGE).

\begin{tabular}{l|l|l|l} 
Dataset & Niche & Ordinary & Popular \\
\hline DATA- & Blue:0.2\% & Blue: $10.3 \%$ & Blue:66.9\% \\
WORLDWIDE & Gray:6.4\% & Gray: $12.6 \%$ & Gray:6.1\% \\
\hline DATA-BRAZIL & Blue:0.0\% & Blue: $5.2 \%$ & Blue:53.9\% \\
& Gray:2.6\% & Gray: $12.4 \%$ & Gray:11.7\%
\end{tabular}




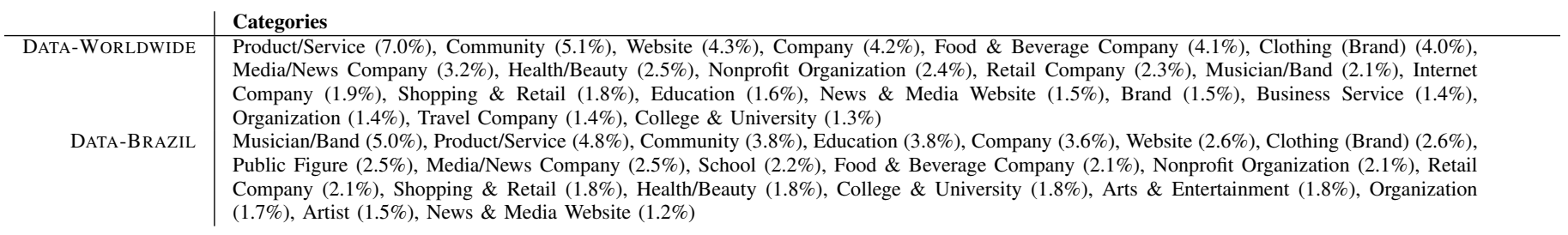

\section{Ethical considerations}

It is important to mention that the code of our developed browser plugins is open source as they can be viewed in the client's machine, as any Chrome and Firefox extension. We only collect information about the ads and clearly state what we collect to the volunteers who install the extensions and accept our terms. All data collection that we present in this paper was reviewed and approved by the Ethical Review Board of the University of Saarland and by the Institutional Review Board of Northeastern University. Due to IRB restrictions, and in order to minimize any risk of exposure of users' sensitive information, we will not share our data or make them publicly available.

\section{WHO ARE THE ADVERTISERS?}

In order to investigate how the platform is being used we first need to be able to characterize the different advertisers that use the platform. We briefly look at the advertisers from two different perspectives, (i) their identity; and (ii) their categories.

\section{A. Advertisers' identity}

Because advertising platforms have been the vectors for privacy violations [31], [40], discriminatory advertising [9], [16], [38], and ad-driven propaganda [19], we begin by examining who the set of advertisers are and what features they have that might indicate their trustworthiness. Estimating the trustworthiness of an advertiser, however, is a difficult task. Facebook offers a platform where anyone with a Facebook account can be an advertiser without going through any verification process. This means that the platform is open to both popular and well-known advertisers as well as niche ones. Additionally, Facebook offers a verification mechanism where anyone who wishes can acquire a verified badge [21]. While popular or verified advertisers are not guaranteed to be trustworthy, we consider the fact that they are more exposed to public scrutiny than the rest as an indication of their potential trustworthiness.

1) Popularity: We consider the number of Likes that advertisers have received on their Facebook Pages as a measure of their popularity; we bin advertisers in three different categories: (1) niche, with $1 K$ Likes or less, (2) ordinary, with between $1 K$ and $100 K$ Likes, and (3) popular, with over $100 K$ Likes.

Niche advertisers constitute $16 \%$ of the Facebook advertisers in our dataset, ordinary $52 \%$, and popular $32 \%(15 \%$; $61 \%$; $24 \%$ for DATA-BRAZIL). While there are more ordinary advertisers than popular in both data sets, popular advertisers place a larger number of ads: $63 \%$ of all unique ads we collected come from popular, $32 \%$ from ordinary and $5 \%$ from niche advertisers (61\%; 35\%; $4 \%$ for DATA-BRAZIL).

2) Verification: There exists two types of verification badges: one blue and one gray. Blue badges are for profiles of public interest figures, and require a copy of an official government-issued photo identification such as a passport. Gray badges are for businesses and require a publicly listed phone number, or a document like phone bill that is associated with the business.

Table $\mathrm{V}$ shows the fraction of verified advertisers for niche, ordinary and popular advertisers. In both datasets niche advertisers tend to be less frequently verified $(0.2 \%$ for blue and $6.4 \%$ for gray verification) compared to ordinary (10.3\% and $12.6 \%$ ) and popular advertisers (66.9\% and 6.1\%). In total, only $26.6 \%$ of advertisers have a blue badge and $9.6 \%$ a gray one; our data shows that a large fraction (38.9\%) of ads come from advertisers that are not verified.

\section{B. Advertisers' categories}

When advertisers on Facebook create a Page, they can selfreport one or more categories that correspond to their business. Advertisers can either choose from a predefined list of 1,543 different categories (organized in a hierarchical tree with a maximum depth of 6) or input a free-text category.

We observe 943 unique categories in our dataset (968 in DATA-BRAZIL). Table IV presents the 20 most common categories among advertisers (they appear in $51.4 \%$ of advertisers in our dataset).

Many advertisers only report a general category such as Website, Company, or Product/Service which are not particularly informative about the sector in which the advertiser works, while others report very fine-grained categories such as Evangelical Church, or Aquarium, or Opera House. To be able to analyze which sectors advertisers come from and to have more homogeneous categories for all, we map advertiser ${ }^{6}$ in our dataset to categories in the Interactive Advertising Bureau (IAB) taxonomy [15]. This taxonomy provides categories for advertising purposes and is a de-facto standard in advertising. It is composed of 29 Tier- 1 categories such as News and Politics or Education. For the Facebook categories Public Figure, Community Organization, NonBusiness Places there is no suitable existing IAB category, so we create a new category. Also, since IAB does not have a Tier-1 categories for all businesses we observe, we created Legal, Other Media, and Entertainment categories as well. For advertisers with only coarse-grained categories such as

${ }^{6}$ You can view the exact mapping we use at https://www.eurecom.fr/ $\sim$ andreou/data/ndss2019.html 
TABLE VI. POPULAR AND SENSITIVE (IN BOLD) IAB ADVERTISER CATEGORIES FOR DATA-WORLDWIDE.

\begin{tabular}{l|r|r} 
IAB Tier-1 category & Advertisers & Ads \\
\hline Food and Drink & $9.3 \%$ & $6.4 \%$ \\
Style \& Fashion & $8.5 \%$ & $5.8 \%$ \\
Technology and Computing & $8.4 \%$ & $9.7 \%$ \\
Community Organization & $8.2 \%$ & $5.0 \%$ \\
Shopping & $6.7 \%$ & $5.2 \%$ \\
News and Politics & $5.5 \%$ & $8.6 \%$ \\
Travel & $4.6 \%$ & $2.9 \%$ \\
Education & $4.4 \%$ & $5.8 \%$ \\
Healthy Living & $4.2 \%$ & $2.5 \%$ \\
Home \& Garden & $3.6 \%$ & $2.2 \%$ \\
\hline \hline Business and Finance & $2.0 \%$ & $2.2 \%$ \\
Medical Health & $1.2 \%$ & $0.6 \%$ \\
Legal & $0.2 \%$ & $0.1 \%$ \\
Religion and Spirituality & $0.1 \%$ & $0.0 \%$
\end{tabular}

Company or Website we do not assign to them any IAB category. In total we manage to map $83 \%$ advertisers to a IAB category $(86.1 \%$ for DATA-BRAZIL).

Advertisers from some categories have the potential to influence users' decisions on important personal and societal issues. For example, political advertisers could influence how users vote, and medical advertisers could affect an individual's decisions about treatment. We consider News and Politics, Education, Medical Health, Legal, Religion and Spirituality, and Business and Finance categories as sensitive. While we do not claim that advertisers from sensitive domains should not send ads, we aim to pay specific attention in our analysis to such categories.

Tables $\mathrm{VI}$ and $\mathrm{VII}$ present the top 10 IAB categories and the respective percentage of advertisers and ads that appear in our datasets. The tables also show (in the bottom) sensitive categories such as Legal that are not part of the top 10. The tables show that 7 out of the top 10 IAB categories are the same in the two datasets. Besides, there is a significant number of advertisers and ads that come from potentially sensitive categories such as News and Politics $(8.6 \%)$ or Education. Finally, the four sensitive categories Business and Finance, Medical Health, Legal, and Religion and Spirituality each constitute a minority of ads but add up to $3-4 \%$ of the ads, which (given that each user receives a median of 11.1 ads per day) still represents up to 3 ads per week.

\section{Takeaways}

The ecosystem of advertisers in Facebook is broad and complex. There exists advertisers who are popular, verified, and more likely to be trustworthy. On the other side, there exist many niche and unverified advertisers for which it is difficult to estimate the trustworthiness without manual effort. We also see that a non-negligible fraction of advertisers are part of potentially sensitive categories such as politics, finance, health, legal and religion (adding up to $\sim 10 \%$ ). Taken together, our analysis points to the fact that users receive ads from advertisers that might concern sensitive information and whose quality is difficult to assess, making it even more important to investigate how such advertisers are using the system.
TABLE VII. POPULAR AND SENSITIVE (IN BOLD) IAB ADVERTISER CATEGORIES FOR DATA-BRAZIL.

\begin{tabular}{|c|c|c|}
\hline IAB Tier-1 category & Advertisers & Ads \\
\hline Education & $10.2 \%$ & $10.9 \%$ \\
\hline Food and Drink & $8.1 \%$ & $6.3 \%$ \\
\hline Music and Audio & $7.6 \%$ & $3.2 \%$ \\
\hline Community Organization & $6.8 \%$ & $4.7 \%$ \\
\hline Technology and Computing & $6.8 \%$ & $7.9 \%$ \\
\hline Shopping & $6.8 \%$ & $6.6 \%$ \\
\hline Style \& Fashion & $5.9 \%$ & $4.9 \%$ \\
\hline News and Politics & $5.8 \%$ & $6.8 \%$ \\
\hline Public Figure & $5.1 \%$ & $3.9 \%$ \\
\hline Entertainment & $3.6 \%$ & $3.1 \%$ \\
\hline Medical Health & $2.3 \%$ & $1.0 \%$ \\
\hline Business and Finance & $1.6 \%$ & $2.5 \%$ \\
\hline Legal & $0.4 \%$ & $0.2 \%$ \\
\hline Religion and Spirituality & $0.3 \%$ & $0.1 \%$ \\
\hline
\end{tabular}

\section{HOW ARE THE ADVERTISERS TARGETING USERS?}

For the different types of advertisers identified in Section IV, we analyze (1) how they target users; (2) which users they target; and (3) how they customize their ads.

\section{A. Analysis of targeting strategies}

1) Breakdown of targeting types: Advertisers on Facebook can choose from a wide range of ways to reach users - see Section II for more details. To analyze the different ways advertisers reach people, we mine the ad explanations provided by Facebook using the "Why am I seeing this?" feature [22]. Facebook ad explanations, despite their limitations, reveal part of the advertisers' targeting (see Section III-B); using the results of prior work [22], we can draw useful conclusions.

By looking at the patterns of ad explanations as well as information in the Facebook Advertising Interface, we have group the individual targeting mechanisms discussed in Section II into several broad targeting types:

Age/Gender/Location - when advertisers target users based on their age, gender, and location.

Attribute-based - when advertisers target users that satisfy a precise list of targeting attributes. We split this in 5 subcategories based on the source of data: Behaviors, Demographics and Interests, which corresponds to attributes inferred by Facebook from the user's activities on the platform; Data brokers [20], which corresponds to targeting based on attributes inferred by external data brokers and not by Facebook 7 , and Profile data, which corresponds to information users provided in their Facebook profiles such as marital status, employer, or university attended.

PII-based - when advertisers target their ads via Custom Audiences that consist of lists of PII including emails or postal addresses.

Retargeting - when advertisers target users who already interacted with their business such as users that visited their page, or used their mobile app.

\footnotetext{
${ }^{7}$ The data brokers that have partnered with Facebook in Europe, US, and Brazil are Acxiom [2], Epsilon [6], Experian [7] and Oracle Data Cloud [18
} 


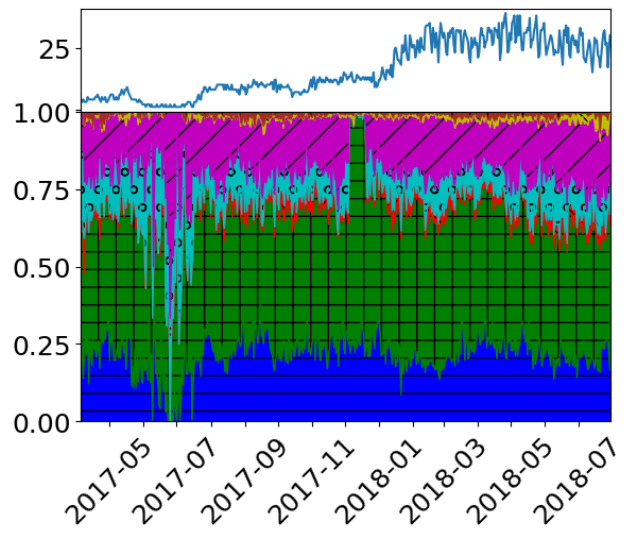

(a) DATA-WORLDWIDE.

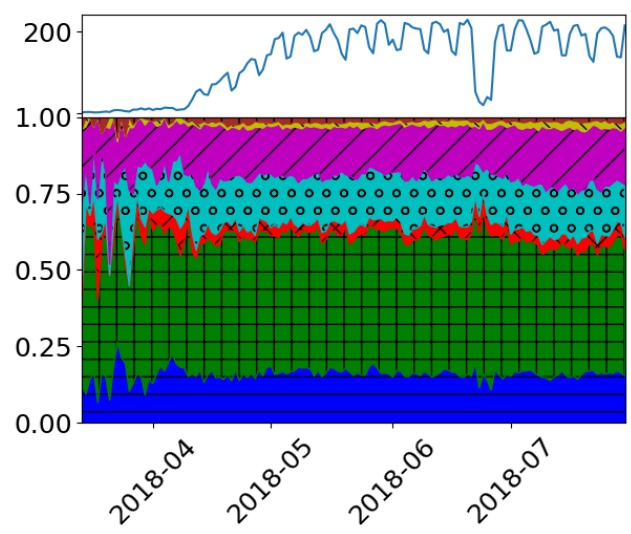

(b) DATA-BRAZIL.

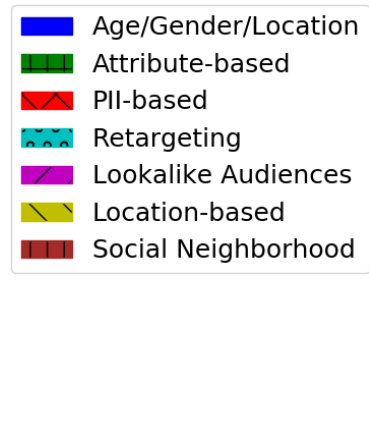

(c) Labels.

Fig. 2. Breakdown of targeting types across time with respect to the number of ads (across all users). Above: daily number of active users.

TABLE VIII. BREAKDOWN OF TARGETING TYPES WITH THE RESPECTIVE FRACTION OF ADS, ADVERTISERS, AND USERS WHO WERE TARGETED. THE LAST COLUMN PRESENTS THE ATTRIBUTE PRECEDENCE ( 1 IS HIGHEST PRECEDENCE; 5 IS LOWEST PRECEDENCE; UNK. IS NOT KNOWN).

\begin{tabular}{l|rrr|r} 
& Ads & Advs. & Users & Prec. \\
\hline Age/Gender/Location & $19 \%$ & $32 \%$ & $95 \%$ & 1 \\
Behaviors & $1 \%$ & $1 \%$ & $7 \%$ & 4 \\
Demographics & $1 \%$ & $1 \%$ & $5 \%$ & 1 \\
Interests & $39 \%$ & $52 \%$ & $96 \%$ & 2 \\
Profile Data & $5 \%$ & $7 \%$ & $84 \%$ & unk. \\
Data Brokers & $1 \%$ & $2 \%$ & $45 \%$ & unk. \\
PII-based & $3 \%$ & $2 \%$ & $79 \%$ & 3 \\
Retargeting & $12 \%$ & $10 \%$ & $92 \%$ & unk. \\
Lookalike Audiences & $17 \%$ & $16 \%$ & $95 \%$ & unk. \\
Location-based & $2 \%$ & $5 \%$ & $64 \%$ & unk. \\
Social Neighborhood & $2 \%$ & $5 \%$ & $60 \%$ & unk.
\end{tabular}

Lookalike audiences - when advertisers let Facebook choose their audience based on past results and the characteristics of previous audiences.

Location-based - when advertisers target users who were at or passed by a precise GPS location.

Social neighborhood - when advertisers target users whose friends liked their Facebook page.

Figures $2 \mathrm{a}$ and $2 \mathrm{~b}$ present a timeline of daily frequency of each targeting type with respect to the total number of ads we collected each day (accompanied by the respective daily number of active users). In general, the proportion of each targeting type does not change substancially over time or over dataset and is fairly consistent across our two data sets 8 Table VIII shows the overall frequency of each targeting type with regard to the number of ads that have been targeted and fraction of advertisers that have used these targeting types, as well as the fraction of users that have been targeted with these types for both datasets combined.

${ }^{8}$ The large increase for Attribute-based around December and January 2018 can be attributed to a possible bug from Facebook, where many explanations from different advertisers showed the same demographic attribute, namely Member of a Family-based household.
Impact of biases and limitations in the dataset: In the fifth column of Table VIII we show the precedence of each targeting types according to prior work [22]. In case of multitype/multi-attribute targeting (e.g., advertisers that use both PII-based and attribute-based targeting at the same time), Facebook only shows one reason in the corresponding explanations (see Section III). The way Facebook selects the reason shown impacts the frequencies reported in the table. According to [22] the multi-type targeting precedence is: Demographics \& Age/Gender/Location $>$ Interests $>$ PIIbased $>$ Behaviors. All targeting types with a precedence other than 1 are therefore possibly underestimated. We do not know how often advertisers are using multi-type targeting, so we cannot estimate the degree of underestimation.

We acknowledge that some of the biases of our population (see Section III-B might affect the proportions, especially for some types like Lookalike audiences and Retargeting which might depend heavily on the activity of a user. However, the fact that there are no large fluctuations, and in general the proportion of each type does not change significantly over time or across datasets gives us confidence that the numbers we see in this section are not overly biased by the population in our datasets.

Looking at more detail at Table VIII we can observe that:

(1) Age/Gender/Location (19\% of ads) and Attribute-based (47\% of ads, with Interests taking the biggest share at 39\%) are the most prevalent targeting types. These targeting types are the two most traditional ways of targeting users online.

(2) A substancial fraction (17\%) of ads are targeted using Lookalike audiences. This is a newer targeting strategy employed by social media advertising platforms that allows advertisers to ask Facebook to choose who to send the ad to based on previous ad campaigns [1]. This targeting mechanism is problematic because the algorithm behind Lookalike audiences is unknown to the public and users have no way of knowing why they received such an ad. On top of this, it has been shown that Lookalike audiences are vulnerable to deceptive advertisers that can use the mechanism to increase the discrimination in their targeting [38]. 
TABLE IX. BREAKDOWN OF TARGETING TYPES SPLIT GEOGRAPHICALLY; WITH THE RESPECTIVE FRACTION OF ADS, ADVERTISERS AND USERS

\begin{tabular}{|c|c|c|c|c|c|c|c|c|c|c|c|c|}
\hline & \multicolumn{3}{|c|}{ Europe (85 users) } & \multicolumn{3}{|c|}{$\begin{array}{c}\text { TARGETED. } \\
\text { North America (16 users) }\end{array}$} & \multicolumn{3}{|c|}{ Brazil (495 users) } & \multirow{2}{*}{$\begin{array}{c}\text { Rest of } \\
\text { Ads }\end{array}$} & \multicolumn{2}{|c|}{ World (12 users) } \\
\hline & Ads & Advs. & Users & Ads & Advs. & Users & Ads & Advs. & Users & & Advs. & Users \\
\hline Age/Gender/Location & $24 \%$ & $35 \%$ & $98 \%$ & $19 \%$ & $25 \%$ & $94 \%$ & $16 \%$ & $28 \%$ & $94 \%$ & $18 \%$ & $28 \%$ & $75 \%$ \\
\hline Behaviors & $1 \%$ & $2 \%$ & $39 \%$ & $1 \%$ & $1 \%$ & $31 \%$ & $0 \%$ & $0 \%$ & $0 \%$ & $1 \%$ & $2 \%$ & $50 \%$ \\
\hline Demographics & $2 \%$ & $3 \%$ & $27 \%$ & $1 \%$ & $2 \%$ & $31 \%$ & $0 \%$ & $0 \%$ & $0 \%$ & $1 \%$ & $3 \%$ & $33 \%$ \\
\hline Interests & $37 \%$ & $48 \%$ & $94 \%$ & $23 \%$ & $36 \%$ & $88 \%$ & $41 \%$ & $55 \%$ & $97 \%$ & $41 \%$ & $48 \%$ & $92 \%$ \\
\hline Profile data & $7 \%$ & $8 \%$ & $88 \%$ & $4 \%$ & $6 \%$ & $88 \%$ & $4 \%$ & $5 \%$ & $83 \%$ & $9 \%$ & $11 \%$ & $75 \%$ \\
\hline Data brokers & $1 \%$ & $1 \%$ & $28 \%$ & $2 \%$ & $4 \%$ & $50 \%$ & $1 \%$ & $2 \%$ & $49 \%$ & $0 \%$ & $0 \%$ & $0 \%$ \\
\hline PII-based & $2 \%$ & $1 \%$ & $73 \%$ & $6 \%$ & $5 \%$ & $81 \%$ & $3 \%$ & $2 \%$ & $80 \%$ & $2 \%$ & $2 \%$ & $67 \%$ \\
\hline Retargeting & $8 \%$ & $7 \%$ & $80 \%$ & $13 \%$ & $13 \%$ & $94 \%$ & $15 \%$ & $12 \%$ & $95 \%$ & $10 \%$ & $10 \%$ & $92 \%$ \\
\hline Lookalike audiences & $17 \%$ & $17 \%$ & $92 \%$ & $30 \%$ & $33 \%$ & $100 \%$ & $17 \%$ & $14 \%$ & $96 \%$ & $15 \%$ & $19 \%$ & $83 \%$ \\
\hline Location-based & $1 \%$ & $3 \%$ & $71 \%$ & $2 \%$ & $3 \%$ & $50 \%$ & $2 \%$ & $6 \%$ & $63 \%$ & $1 \%$ & $2 \%$ & $50 \%$ \\
\hline Social neighborhood & $1 \%$ & $3 \%$ & $51 \%$ & $1 \%$ & $2 \%$ & $62 \%$ & $2 \%$ & $8 \%$ & $61 \%$ & $1 \%$ & $4 \%$ & $58 \%$ \\
\hline
\end{tabular}

(3) A non-trivial fraction (12\%) of ads are part of Retargeting, meaning an advertiser is trying to reach a user who had previously interacted with them.

(4) While a small share of ads (3\%) are part of PII - based targeting (note that this targeting type has one of the lowest precedences and it is underestimated), a large number of users (79\%) have been targeted with at least one PII - based ad (i.e., there exists at least one advertiser that knows the email or the phone number or some other identifiable information about the user). To date, there is no verification process of how advertisers gathered such information and lists of phone numbers and emails can be easily bought online [10]. It is important to give special attention to this targeting mechanism especially because it has been shown that it can be used for discriminatory advertising [38] and has been exploited to leak users' personal information [40].

(5) Surprisingly, Social neighborhood targeting only accounts for a very small fraction of ads $(2 \%)$. This is somewhat unexpected as this is a marketing strategy for which social media have a competitive advantage over traditional advertising.

In addition, Table $\mathrm{IX}$ presents the frequency of each targeting type in terms of ads, advertisers and users in Europe, North America, Brazil, and the rest of the world ${ }^{9}$ We see that:

(1) Data brokers and PII-based targeting types seem more frequent in North America, reaching 2\% and 6\% of the ads, respectively (compared to $1 \%$ and $2 \%$ in Europe). PII-based targeting types seem more prominent among users as well: $81 \%$ of our North American users have received such ads, while there only $73 \%$ Europeans have. This might reflect the differences regarding privacy laws and handling of personal data in general [11].

(2) European advertisers appear to use Retargeting and Lookalike audiences less frequently and Age/gender/location more frequently. This is intriguing as it might show that current privacy discussions and laws [11] have an impact on European advertisers' strategies.

2) Persistent vs. one-shot targeting: We define a persistent advertiser as an advertiser that has advertised to at least one user over a period of more than two weeks and with more

\footnotetext{
${ }^{9}$ Note that we assume that the precedence we observe in explanations is consistent across countries.
}

than five ads; we similarly define a one-shot advertiser as an advertiser that targeted all users no more than once.

Impact of biases and limitations in the dataset: In order not to overestimate the fraction of one-shot advertisers we report results on only advertisers for users for which we have more than 2 weeks of data. We also looked at one-shot advertisers for users for which we have more than 4 and 6 weeks of data and the results are similar so we omit them.

Our results show that the large majority of advertisers $(65 \%)$ are one-shot and only a small minority $(3 \%)$ are observed persistently targeting users $(64 \%$ and $4 \%$, respectively, for DATA-BRAZIL). The vast majority (88\%) of persistent advertisers have persistently targeted only one or two users; however, some have targeted persistently up to 17 users in DATA-WORLDWIDE and 63 in DATA-BRAZIL (these include Facebook, Netflix, Google, and Udemy). Table X compares the characteristics of the two types of advertisers for both datasets combined. We can see the following:

Popularity: In general, persistent advertisers are more popular and are more likely to be verified, but there exist also persistent advertisers who are niche(e.g., SEMY Awards, an organization that gives industry awards; and Vianex-Fast-Remit, a money transfer company with only 53 Likes).

Targeting types: We observe that persistent advertis-

TABLE $X . \quad$ CHARACTERISTICS OF PERSISTENT AND ONE-SHOT ADVERTISERS.

\begin{tabular}{l|l|l} 
& Persistent & One-shot \\
\hline Verified & $61 \%$ & $24 \%$ \\
Popular/Ordinary/Niche & $67 \% / 31 \% / 2 \%$ & $19 \% / 59 \% / 22 \%$ \\
\hline Top targeting types & Attr-based 44\% & Attr-based 51\% \\
& Retargeting 18\% & Retargeting 3\% \\
& A/G/L 17\% & A/G/L 27\% \\
& Lookalike 16\% & Lookalike 10\% \\
& PII 5\% & PII 1\% \\
& Social n. 1\% & Social n. 4\% \\
& Location 1\% & Location 4\% \\
\hline Top IAB categories & Tech.\&Comp. 11\% & Food \& Dr. 8\% \\
& News \& Pol. 10\% & Comm. Org. 8\% \\
& Food \& Dr. 9\% & Education 7\% \\
& Style \& F. 8\% & Style \& F. 7\% \\
& Education 8\% & Shopping 7\%
\end{tabular}


TABLE XI. TARGETING TYPES AND TOP TWO IAB CATEGORIES WRT FRACTION OF ADVERTISERS IN EACH CATEGORY.

\begin{tabular}{l|l|l}
\multirow{2}{*}{ Type } & DATA-WORLDWIDE & DATA-BRAZIL \\
\hline \multirow{3}{*}{ Data brokers } & Automotive: 8.7\% & Business \& Fin.: 7.7\% \\
& Business \& Fin.: 5.9\% & Automotive: 5.7\% \\
\cline { 2 - 3 } PII-based & Video Gaming: 6.5\% & Business \& Fin.: 8.2\% \\
& Tech. \& Comp.: 3\% & Video Gaming: 6.9\% \\
\cline { 2 - 3 } Lookalike a. & $\begin{array}{l}\text { Tech. \& Comp.: 31.9\% } \\
\text { Business \& Fin.: 31.2\% }\end{array}$ & Business \& Fin.: 27.7\% \\
& Careers: 25\%
\end{tabular}

ers use PII-based and Retargeting more frequently and Age/Gender/Location less frequemently (compared to Table VIII). For one-shot advertisers, we observe that they use Age/Gender/Location and Attribute-based more frequently, and Lookalike audiences, PII-based and Retargeting less frequently. Surprisingly, a large fraction (8\%) of targeting types for one-shot advertisers are Location-based and Social neighborhood (compared to $4 \%$ in Table VIII).

Advertisers' IAB categories: $10 \%$ of persistent advertisers are part of the News and Politics IAB category (e.g., PokerGO, a Facebook page that covers news in Poker; Vanessa Grazziotin, a Brazilian politician; the European Parliament); while only $5 \%$ of one-shot advertisers are part of this category. Regarding more sensitive categories, there exist 13 Medical Health persistent advertisers such as THINX (related to women's health), and Merck Group (a pharmaceutical company).

In the next section, we discuss how the text of the ads changes across time when a user receives multiple ads from the same advertiser.

3) Who targets what types?: In this section we investigate which advertisers use opaque and more invasive targeting types such as Data brokers, PII-based and Lookalike audiences more frequently. Table XI shows for each targeting type the top two advertiser categories with regards to the fraction of advertisers from the category that have used the respective targeting type. Overall, we see that the IAB categories of advertisers that make use of such targeting types are consistent across datasets and include a sensitive category, Business and Finance. Advertisers in Automotive $(8.7 \% ; 5.7 \%$ in DATA-BRAZIL) and Business and Finance (5.9\%; $7.7 \%$ in DATA-BRAZIL), use Data brokers more frequently in both datasets. In all cases it is a significant increase compared to $2 \%$ of all advertisers which overall use Data brokers (Table VIII).

Automotive advertisers that use Data brokers include many well known companies like Opel, Volkswagen, and Peugeot, indicating a possible industry practice, since data brokers are known to collect data about vehicle ownership [22]. Business and Finance advertisers, which also use Lookalike audiences very frequently in both datasets $(31.2 \%$ in DATA-WORLDWIDE and $27.7 \%$ in DATA-BRAZIL), include insurance companies like AXA Deutschland, financial services like germantaxes.de and banks like Santander Brasil.

4) Takeaways: Thus far, we have observed a variety of marketing practices by advertisers both big and small. The targeting mechanisms sometimes invasive (e.g. PII-based, Data brokers) and often opaque (e.g. Lookalike audiences). The data used from targeting comes from a multitude of sources: advertisers (e.g. PII-based), the ad platform (e.g. Interests),
TABLE XII. TOP TARGETING ATTRIBUTES (I FOR Interests, B FOR Behaviors, D FOR Demographics, PD FOR Profile data) WRT THE FRACTION OF ADS, ADVERTISERS, USERS FOR DATA-WORLDWIDE.

\begin{tabular}{|c|c|c|}
\hline & Attribute & Fraction \\
\hline \multirow{11}{*}{$\begin{array}{l}\text { Attributes present } \\
\text { in Ads }\end{array}$} & English (US)-PD & $8.4 \%$ \\
\hline & Travel-I & $3.5 \%$ \\
\hline & Food and drink-I & $3.5 \%$ \\
\hline & Shopping and fashion-I & $3.1 \%$ \\
\hline & French (France)-PD & $2.5 \%$ \\
\hline & Online shopping-I & $2.3 \%$ \\
\hline & Entertainment-I & $2.1 \%$ \\
\hline & Memb. of a family-based household-D & $2.0 \%$ \\
\hline & Technology-I & $1.9 \%$ \\
\hline & Music-I & $1.3 \%$ \\
\hline & Sports-I & $1.1 \%$ \\
\hline \multirow{11}{*}{$\begin{array}{l}\text { Attributes used } \\
\text { by Advertisers }\end{array}$} & English (US)-PD & $6.6 \%$ \\
\hline & Travel-I & $4.7 \%$ \\
\hline & Shopping and fashion-I & $3.9 \%$ \\
\hline & French (France)-PD & $3.6 \%$ \\
\hline & Memb. of a family-based household-D & $3.2 \%$ \\
\hline & Food and drink-I & $3.1 \%$ \\
\hline & Online shopping-I & $3.1 \%$ \\
\hline & Entertainment-I & $3.0 \%$ \\
\hline & Technology-I & $2.4 \%$ \\
\hline & Music-I & $2.3 \%$ \\
\hline & Sports-I & $2.0 \%$ \\
\hline \multirow{11}{*}{$\begin{array}{l}\text { Attributes used } \\
\text { to target Users }\end{array}$} & English (US)-PD & $79.3 \%$ \\
\hline & Travel-I & $63.1 \%$ \\
\hline & Entertainment-I & $59.5 \%$ \\
\hline & Technology-I & $56.8 \%$ \\
\hline & Shopping and fashion-I & $49.5 \%$ \\
\hline & Online shopping-I & $49.5 \%$ \\
\hline & Food and drink-I & $49.5 \%$ \\
\hline & Sports and outdoors-I & $47.7 \%$ \\
\hline & Music-I & $47.7 \%$ \\
\hline & Sports-I & $46.8 \%$ \\
\hline & Movies-I & $41.4 \%$ \\
\hline
\end{tabular}

and third parties (e.g. Data brokers). There are differences in targeting strategies across countries: more users are targeted with PII-based and Data brokers in the U.S. than Europe and the rest of the world. Finally, advertisers from specific industries like Business and Finance use such invasive and opaque strategies significantly more frequently.

\section{B. Analysis of targeting attributes}

We now study the precise attributes advertisers use to create their targeting audiences, and the different ways advertisers are using them. There are four types of attributes according to the Facebook Advertiser API: Interest (I), Behaviors (B), Demographics $(D)$ and Profile data $(P D)$. We analyze data on $12 \mathrm{~K}$ advertisers which have targeted 111 users with $38 \mathrm{~K}$ ads that have used 2,552 attributes $(14 \mathrm{~K} ; 499 ; 55 \mathrm{~K}$; and 4,239 for DATA-BRAZIL, respectively).

Impact of biases and limitations in the dataset: We collect the attributes present in the ad explanations provided by Facebook. Andreou et al. [22] showed that if the advertiser uses multiple attributes to create his targeting audiences, only the attribute with the highest audience size will appear in the explanation. Thus all the results in the section are likely to be biased towards the popular attributes advertisers choose (as those will be shown if the advertisers use multiple attributes). Additionally, possible biases of the population of our datasets might be reflected on specific attributes.

\section{1) Attributes advertisers use:}

Most and least used attributes: Table XII shows the 10 attributes that appear most frequently in ad explanations (top), 
TABLE XIII. SAMPLE OF ATTRIBUTES THAT HAVE APPEARED IN JUST ONE AD EXPLANATION.

\begin{tabular}{|c|c|}
\hline Attribute Type & Attributes \\
\hline Interests & $\begin{array}{l}\text { Pokémon Yellow, Company, Capgemini, Artisan, Underwater diving, W9 (TV channel), Serge Gainsbourg, Fighting game, Modernism, Adobe } \\
\text { After Effects }\end{array}$ \\
\hline Behaviors & $\begin{array}{l}\text { Expats (Italy), Nexus 5, New smartphone and tablet owners, Huawei, Xiaomi, Anniversary in 61-90 Days, Returned from trip } 1 \text { week ago, Small } \\
\text { business owners, Uses a mobile device (18-24 months), Samsung, Expats (Colombia) }\end{array}$ \\
\hline Demographics & Upcoming birthday, Anniversary within 30 Days, Birthday in 01 January, Close Friends of Women with a Birthday in 7-30 days \\
\hline Profile data & Student, Professor, Japanese, Northeastern University, Croatian, CTO, UPMC Paris, IIT Kharagpur, UCLA \\
\hline
\end{tabular}

TABLE XIV. ADVERTISERS Who USE THE Highest NUMBER OF ATtRibutes.

\begin{tabular}{|c|c|c|c|}
\hline Dataset & Name & Nb Attr. & Sample of Attributes \\
\hline $\begin{array}{l}\text { DATA- } \\
\text { WORLDWIDE }\end{array}$ & Google & 94 & $\begin{array}{l}\text { Harvard Business Review (I), Graduation (I), Master's degree (PD), Digital media (I), Politics and social issues } \\
\text { (I), Women's rights (I),Hacker News (I), US politics (very liberal) (D), Married (PD), Family (I) }\end{array}$ \\
\hline DATA-BRAZIL & Udemy & 105 & $\begin{array}{l}\text { Web development (I), Audio mastering (I), Python (programming language) (I), Microsoft Word (I), First- } \\
\text { person shooter games (I), Data analysis (I), Artificial intelligence (I), Digital art (I), Network security (I), } \\
\text { Thich Nhat Hanh (I), Dalai Lama (I), Creativity (I) }\end{array}$ \\
\hline
\end{tabular}

were used by the largest fraction of advertisers (middle), and were seen by the largest number of users in their ad explanations (bottom) out of those considered in Section $\mathrm{V}-\mathrm{B}$. We can see that most attributes are either languages, or broad Interests such as Travel and Entertainment. Regarding the least used attributes, $38 \%$ of them appear in only one ad (Table XIII presents a sample); $49 \%$ have been used by only one advertiser; and $64 \%$ have been seen by only one user $(36 \% ; 49 \%$; and $48 \%$ for DATA-BRAZIL). Such attributes typically appear more specific (e.g. interests like Artisan, Modernism, or profile data that point to specific universities) than the most frequently used attributes, revealing characteristics of users that might make them more unique. Furthermore, the sparse occurrences of these individual attributes highlights the fact that unless users look at ad explanations constantly, they are going be oblivious of most of the attributes used to target them.

Predefined vs free-text interests: As mentioned in Section II-A Interests can either be predefined or free-text. In our dataset, a surprising fraction of ads (39\%) was targeted using free-text interests while $61 \%$ targeted using predefined ones (47\%; 53\% for DATA-BRAZIL). The percentage of free-text interests is likely underestimated given they have generally a smaller audience sizes than predefined ones with a median of $203 \mathrm{M}$ users for predefined, and $17 \mathrm{M}$ for free-text that were used for targeting in our dataset. It is worth noting that freetext attributes can be used as a proxy to discriminate against people [38] and can also be more sensitive.

2) Consistency of attributes being used by advertisers: We now take a deeper look at how consistent are the attributes that advertisers use both individually, and within their respective IAB category.

Individual advertisers' attributes: While we cannot always know all the attributes advertisers use for the same ad campaign (due to the limitations of ad explanations), we can check whether multiple attributes appear in multiple campaigns of an advertiser. In our dataset $24 \%$ of advertisers have used more than one attribute across all their observed ad campaigns with some targeting even more than 15 different attributes. Table XIV shows the advertisers that have used the largest number of attributes in both datasets, including Google with 94, and Udemy with 105 attributes. While many of the attributes used seem relevant to the business scope of the respective advertiser, some of them are more questionable. For example, Google has used attributes such as Married, Family, Women's rights, Politics and social issues and US
TABLE XV. CONSENSUS AMONG THE ATTRIBUTES THAT ADVERTISERS OF AN IAB CATEGORY USE MEASURED BY KRIPPENDORFF'S $\alpha$ (NORMALIZED).

\begin{tabular}{l|r|r} 
IAB category & DATA-WORLDWIDE & DATA-BRAZIL \\
\hline Food and Drink & $21.5 \%$ & $13.7 \%$ \\
Style \& Fashion & $32.4 \%$ & $21.6 \%$ \\
Technology and Comput. & $9.3 \%$ & $5.9 \%$ \\
Community Org. & $5.4 \%$ & $3.6 \%$ \\
Shopping & $11.5 \%$ & $8.5 \%$ \\
News and Politics & $9.1 \%$ & $4.0 \%$ \\
Travel & $59.8 \%$ & $37.1 \%$ \\
Education & $9.3 \%$ & $9.8 \%$ \\
Healthy Living & $22.4 \%$ & $14.5 \%$ \\
Home \& Garden & $12.6 \%$ & $9.4 \%$ \\
\hline \hline Business and Finance & $8.1 \%$ & $12.4 \%$ \\
Medical Health & $15.2 \%$ & $11.1 \%$ \\
Legal & $4.6 \%$ & $17.4 \%$ \\
Religion and Spirituality & $13.6 \%$ & $7.8 \%$
\end{tabular}

politics (very liberal) to target users. Similarly Udemy has used attributes such as Dalai Lama and Thich Nhat Hanh which might reflect specific religious groups and political world-views. We will investigate in the next section how the ads of advertisers vary with the targeting attributes they use.

$I A B$ categories' attributes: Advertisers that belong to the same IAB category, intuitively might have some consensus on the attributes they use, which would reflect the category they belong to. We use Krippendorff's $\alpha$ reliability coefficient [32] to measure the amount of agreement between advertisers that belong to the same IAB category. Values for $\alpha$ typically range between 0 and 1 , with $\alpha=1$ implying perfect consensus among the attributes that advertisers in a category are using and $\alpha=0$ implying that the attributes each advertiser is using are not statistically related. Table XV shows the $\alpha$ (normalized) of advertisers in the top $10 \mathrm{IAB}$ as well as sensitive categories. We normalize the values by dividing by the the highest $\alpha$ in our datasets which corresponds to the Pets category $(0.17$ for DATA-WORLDWIDE; 0.20 for DATA-BRAZIL). We see the highest consensus between advertisers in Travel and Style \& Fashion with $59.8 \%$ and $32.4 \%$ respectively $(37.1 \% ; 21.6 \%$ for DATA-BRAZIL). In fact, out of the 632 Travel advertisers, $37 \%$ has used the interest Travel and $10 \%$ the interest All frequent travelers.

Regarding more sensitive categories, we see that most of them have in general lower consensus. The most common attribute out of the 591 attributes that News and Politics 
TABLE XVI. FRACTION OF ADVERTISERS THAT BELONG TO DIFFERENT IAB CATEGORIES AND CHANGE THE CONTENT OF THEIR ADS ACROSS TIME, USERS AND ATTRIBUTES.

\begin{tabular}{l|lll|lll} 
& \multicolumn{3}{|c|}{ WORLDWIDE } & \multicolumn{3}{c}{ BRAZIL } \\
IAB category & Time & Users & Attr. & Time & Users & Attr. \\
\hline Food \& Drink & $8.1 \%$ & $4.9 \%$ & $11.8 \%$ & $9.4 \%$ & $7.5 \%$ & $8.2 \%$ \\
Style \& Fashion & $13.0 \%$ & $10.8 \%$ & $8.2 \%$ & $6.6 \%$ & $8.5 \%$ & $5.2 \%$ \\
Tech. \& Comp. & $11.5 \%$ & $11.8 \%$ & $9.1 \%$ & $8.8 \%$ & $4.5 \%$ & $6.3 \%$ \\
Community Org. & $6.6 \%$ & $3.9 \%$ & $4.9 \%$ & $4.9 \%$ & $2.0 \%$ & $5.4 \%$ \\
Shopping & $7.6 \%$ & $5.9 \%$ & $7.5 \%$ & $6.7 \%$ & $9.0 \%$ & $8.3 \%$ \\
News \& Politics & $10.9 \%$ & $16.7 \%$ & $9.0 \%$ & $9.9 \%$ & $5.0 \%$ & $7.1 \%$ \\
Travel & $4.7 \%$ & $7.8 \%$ & $6.8 \%$ & $1.9 \%$ & $3.0 \%$ & $3.2 \%$ \\
Education & $5.3 \%$ & $5.9 \%$ & $3.7 \%$ & $11.3 \%$ & $15.6 \%$ & $12.9 \%$ \\
Healthy Living & $3.6 \%$ & $2.9 \%$ & $3.2 \%$ & $2.4 \%$ & $3.0 \%$ & $2.6 \%$ \\
Home \& Garden & $2.2 \%$ & $2.9 \%$ & $2.7 \%$ & $2.0 \%$ & $3.0 \%$ & $2.3 \%$ \\
\hline \hline Business \& Fin. & $2.1 \%$ & $4.9 \%$ & $2.3 \%$ & $1.7 \%$ & $1.5 \%$ & $2.0 \%$ \\
Medical Health & $0.5 \%$ & $0.0 \%$ & $0.9 \%$ & $1.4 \%$ & $1.5 \%$ & $1.5 \%$ \\
Legal & $0.0 \%$ & $0.0 \%$ & $0.1 \%$ & $0.2 \%$ & $0.0 \%$ & $0.3 \%$ \\
Religion \& Spir. & $0.0 \%$ & $0.0 \%$ & $0.0 \%$ & $0.2 \%$ & $0.0 \%$ & $0.2 \%$
\end{tabular}

advertisers have used, is English-Profile data (11\% of advertisers), and the rest of attributes come from a very wide range of topics, such as political like Social Democratic Party of Germany and Anti-fascism, philosophical like Friedrich Nietzsche, or sexual orientation like LGBT community.

3) Takeaways: A large fraction of attributes used in targeting are free-text ones; free-text attributes are often more niche and potentially more sensitive. Additionally, a significant fraction of advertisers use multiple attributes to target users, going to as many as 105 attributes across campaigns. While in most cases the targeting attributes are in accordance with the business of the advertiser, we do find cases of questionable targeting even from big companies. Our findings emphasize the need for mechanisms that can provide more visibility and accountability in what type of users do advertisers target.

\section{Analysis of targeted ads}

Advertisers often tweak the content of their ads in order to get better engagement from users. In this section, we analyze how advertisers change their ads across three dimensions: (1) over time for the same user, (2) across users, and (3) across targeting attributes. These practices are not necessarily malicious, and frequently they might be the result of benign practices such as running several ads to different users to see how they perform. However, the tailoring of ad content may raise concerns in certain contexts such as political advertising; if left unobserved, highly targeted ad messages could become a tool for manipulation. For the remainder of this section, we focus on front ads only, as we observed that the content of front ads and side ads often differs for the same advertiser due to the different formats, and we do not wish to consider such differences as changes to the ads themselves.

1) Ads that change over time for the same user: To measure the percentage of advertisers change the content of their ads over time for a specific user, we look at user-advertisers pairs. Out of the 34K user-advertisers pairs we observe in our dataset, in $34 \%$ of them the advertiser sent two or more ads to a user; we consider this set in this analysis.

To identify advertisers that change the content of their ads, we count the number of ads with different texts for each user-

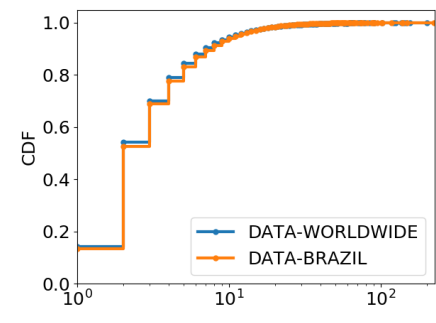

(a) raw

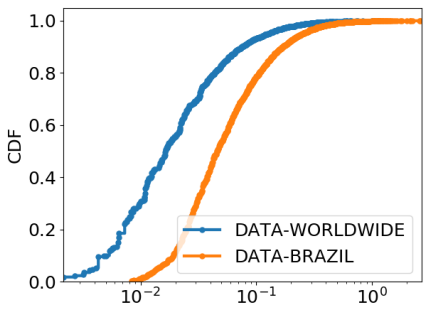

(b) normalized

Fig. 3. Cumulative distribution (CDF) of the number of different texts in ads for each user-advertiser pair.

advertiser. Figure 3 a shows the cumulative distribution of the number of ads with different texts for each user-advertiser pair. The figure shows that $86 \%$ of user-advertiser pairs have two or more ads with different texts (and this corresponds to $86 \%$ of the advertisers we consider). Furthermore, $5.5 \%$ of useradvertiser pairs have more than 10 different ad texts. This result suggests that advertisers are showing users a variety of ads, rather than a single ad repeatedly.

To study the properties of advertisers that change their text frequently, we need to normalize the number of texts in each user-advertiser pair by the number of days in which we have collected ads for the user (as some users provided data for longer periods than others). To do so, we examine advertisers corresponding to the top $10 \%$ of user-advertisers pairs with most text changes in their ads (normalized). This corresponds to 768 advertisers that have targeted 99 users $(1,203$ and 461, respectively, for DATA-BRAZIL). Table XVI shows the most frequent IAB categories of these advertisers in the Time column. For example, we observe that over 13\% of Style \& Fashion advertisers sent different texts to at least one user, and that $10.9 \%$ of advertisers in the potentially sensitive category of News and Politics category did the same.

To provide examples of how these advertisers are changing the content of their ads, the first two rows of Table XVII presents a sample of advertisers and the text of their ads from News and Politics. There, we see an example from the The New York Times where ads are tailored to reflect different news articles, and an example of a politician whose ads are tailored to political messages to relate to her political agenda.

2) Ads that change over users: To analyze the advertisers that change the content of their ads across users, we focus on two subsets of advertisers: (1) all-disjoint, representing advertisers where each user has been targeted with a different ad (i.e., there is no overlap in the ads received by any of the users); and (2) one-disjoint representing advertisers where there exists at least one user that received ads that are different than the rest of the users targeted by the advertiser (i.e. there exists a user with an empty overlap between his ads and the ads received by the rest of the users).

We consider that two ads are different if the text that appears is different. To account for the fact that the text that appears in two ads is different just because it is in two different languages, we only consider ads that are in English. We also repeat the analysis for only ads that are in Portuguese (from DATA-BRAZIL), French and German. In order to detect the 


\begin{tabular}{|c|c|c|}
\hline Name & Att/Usr/Time & Text of ads \\
\hline $\begin{array}{l}\text { New York Times } \\
\text { (News \& Pol.) }\end{array}$ & Time & $\begin{array}{l}\text { "I'm not sure it's possible to justify my liaisons with married men, but what I learned from having them warrants discussion." } \\
\text { (via The New York Times - Modern Love) ** No. 1: Wear comfortable underwear ** A victory for Merkel. But also for the } \\
\text { far-right. ** I'm hoping for a crib death, wrote one user. "Deport the scum immediately," read another online comment. ** "I } \\
\text { have never understood why some guys seem to think flattery is the key to a bedroom they've already been welcomed into." } * * \\
\text { The most innovative newsroom in journalism. And reporters who still knock on doors. ** "Something that started decades ago } \\
\text { and was applauded and inoffensive is now politically incorrect. What can you do" Lisa Simpson says. The shot then pans to a } \\
\text { framed picture of Apu with the line, "Don?t have a cow!" inscribed on it. }\end{array}$ \\
\hline $\begin{array}{ll}\text { Cecilia } & \text { Checha } \\
\text { Merchán } & \text { (News } \\
\text { \& Pol.) } & \end{array}$ & Time & $\begin{array}{l}\text { \# BRAZIL It is an honor to have shared with former Chancellor Celso Amorin, the theologian Leonardo Boff and our Nobel } \\
\text { Peace Prize, Pérez Pérez Esquivel, the return of the "Circuses of democracy". I took the greeting of our people, the strength } \\
\text { of our struggles !, todxs for \# LulaLivre! Ao vivo do Circo da Democracia, na UFPR ** Legal Abortion already !!! Pañuelazo } \\
\text { in Córdoba and throughout the country. We do not want milicos in the streets, never again! \# CordobaPorElAbortoLegal \# } \\
\text { QueSeaLEy \# 8A ... ** Yesterday in Cordoba we marched a crowd to say Never More Milicos in the Streets. ** Macri's } \\
\text { adjustment is not possible without complicit governors like Schiaretti. \# Tarifazo \# Cordoba (translated) }\end{array}$ \\
\hline $\begin{array}{l}\text { Bloomberg } \\
\text { (News \& Pol.) }\end{array}$ & $\begin{array}{l}\text { User } 1 \\
\text { User } 2 \\
\text { User } 3 \\
\text { User } 4 \\
\text { User } 5 \\
\text { User } 6\end{array}$ & $\begin{array}{l}\text { Your petabytes can help you prepare. } * * \text { What IoT developers can learn from Apple. } * * \text { This sector is predicted to surge... ten } \\
\text { times over. ** It will be bigger than the smartphone market. ** Is your company ready to shop for its next digital merger? ** } \\
\text { Elon Musk thinks AI poses the biggest threat to humanity. } \\
\text { Even though Ma "had no business plan." } \\
\text { Just look at Cape Town. } * * \text { The world is more complex than ever, which makes big risks more dangerous. } \\
\text { Offshore oil rigs have a } \$ 38 \text { million problem. ** Only } 3-5 \% \text { of oil and gas equipment is currently connected to the cloud. } \\
\text { This isn't a traditional retirement plan. } \\
\text { A doctor told him to go home to die. }\end{array}$ \\
\hline $\begin{array}{l}\text { eToro (Bus. \& } \\
\text { Fin.) }\end{array}$ & $\begin{array}{l}\text { User } 1 \\
\text { User } 2 \\
\text { User } 3 \\
\text { User } 4\end{array}$ & $\begin{array}{l}\text { Discover a simpler way to invest in stocks from the world's leading markets. Join Now! ** Get many of the advantages of } \\
\text { investing in stocks without the hassle. Join Now! ** Buy fractional shares or copy top investors? portfolios in real time - all } \\
\text { without any ticket or management fees. Join Now! } \\
\text { We make trading Ethereum as simple as trading stocks. Trade Ethereum Online - eToro }{ }^{\mathrm{TM}} \\
3 \% \text { jump on Tesla stocks from a tease? what can happen with the unveil this October? } \\
\text { Smart investors find opportunities everywhere - Don't miss yours! Your Capital is at risk. CFD Trading. }\end{array}$ \\
\hline $\begin{array}{l}\text { VICE } \quad \text { News } \\
\text { (News \& Pol.) }\end{array}$ & $\begin{array}{l}\text { PC Magazine } \\
\text { US politics (very liberal) }\end{array}$ & $\begin{array}{l}\text { As North Korea celebrated its founder's 105th birthday, VICE returned to the Hermit Kingdom to see how its citizens are reacting } \\
\text { to the growing crisis. (via HBO ) ** As North Korea celebrated its founder's 105th birthday, VICE returned to the Hermit } \\
\text { Kingdom to see how its citizens are reacting to the growing crisis. ** There's a giant inflatable Trump Chicken on the south } \\
\text { lawn of The White House . ** It was supposed to be a press conference about infrastructure, but then it took a turn. ** Donald } \\
\text { Trump always seems to say what Donald Trump won't say. } \\
\text { A self-driving, flying taxi could soon be a reality } \\
\text { BuzzFeed News' plan to fight a lawsuit related to the infamous "pee tape" dossier: prove some of the allegations against Donald } \\
\text { Trump are true. ** One of the reasons it's hard for Trump to navigate the guns issue after Parkland is that the gun rights } \\
\text { community itself is still trying to figure out what change is acceptable. } \\
\text { Mr. Trump and Mr. Cohen have a lot of explaining to do. ** VICE News had exclusive access from the front-lines of } \\
\text { Charlottesville, and you can watch the full episode now. (via HBO )** VICE News: We're possibly the only media organization } \\
\text { to be certified as "fake news incorporated" by Sebastian Gorka. (via HBO ) } \\
\text { But can they get it delivered to the International Space Station in } 30 \text { minutes or less? }\end{array}$ \\
\hline $\begin{array}{l}\text { Merck Group } \\
\text { (Medical Health }\end{array}$ & $\begin{array}{l}\text { Master's degree } \\
\text { Startup company }\end{array}$ & $\begin{array}{l}\text { Escape the desk: create an environment where curiosity thrives. \# catchcurious ** Does your business model empower curiosity? } \\
\text { \# catchcurious ** Can curiosity take higher education further? \# catchcurious ** Curiosity as a means of survival? Find out } \\
\text { more: www.curiosity.merckgroup.com/stories/curiosity-and-brain \# catchcurious } \\
\text { How our smart innovations are driving the future of personal mobility. \# alwayscurious } \\
\text { Join us as we collaborate with the humans of tomorrow. \# alwayscurious } * * \text { Imagine your ideas for the future of science and } \\
\text { technology in our Future Visions film... \# alwayscurious ) }\end{array}$ \\
\hline
\end{tabular}

language of a text, we use the Google Translate API [12]. For this analysis, we also consider only advertisers that targeted more than three users.

Out of the 689 advertisers in our dataset that have sent ads in English and have targeted more than three users, $79.4 \%$ are one-disjoint and $14.8 \%$ are all-disjoint. For Portuguese, French and German ads the percentage of all-disjoint advertisers are $5.7 \%, 14.5 \%$ and $15.8 \%$.

We analyze next the all-disjoint advertisers with English ads (Brazilian for DATA-BRAZIL). Table XVI presents the fraction of all-disjoint advertisers that belong to the different IAB categories in the Users column. We can see that News and Politics is the category with the largest fraction of all-disjoint avertisers. Table XVII presents a sample of two advertisers and the text of their ads for different users in the middle two rows. For Bloomberg, we see signs of possible tailoring of the content with regard to each user: all ads User 1 has received are related to IT news, while User 3, has received only ads that are about oil rigs. With eToro we do not see such signs of tailoring, as all ads are related to stocks and trading. While we see a large fraction of one or all-disjoint advertisers, we cannot check whether the content of the ads has been tailored for each exact user or it results from some broader benign targeting strategy. Regardless, users do end up seeing different ads from the same advertiser which might end up influencing them in unknown (and potentially nefarious) ways ${ }^{10}$

3) Ads that change over targeting attributes: As a final point of analysis, we examine how the advertiser's different targeting strategies relate to the ad text. In other words, do the advertisers create custom text when they choose different targeting attributes, or do they tend to re-use the same ad text across multiple attributes?

To do so, we first consider advertisers who we observed to use multiple different targeting attributes. We then calculate the fraction of advertisers who never use the same ad text with different attributes (i.e., those advertisers who we observe to always have their ad text differ when they use different attributes). Out of the 2,487 advertisers we considered, $64.7 \%$ are observed to do so $(3,949$ and $50.3 \%$ for DATA-BRAZIL). Table XVI presents the fraction of such advertisers that belong

\footnotetext{
${ }^{10}$ Imagine one user always receiving ads from a news organization about unlawful immigrants, while another receives ads with news about foreign startups.
} 
to the different IAB categories in the Attr. column. Once more News and Politics advertisers show this behavior more frequently than most other categories.

In the bottom two rows of Table XVII we present a sample of advertisers and the text of their ads for different targeting attributes from the News and Politics and Medical Health. In the case of VICE News we see a clear tailoring of the ads in accordance to the targeting attribute: for attributes like Democratic Party or US politics (very liberal) we see more political oriented ads, and for PC Magazine we see ads related to technology. However with Merck Group, even though they change the ad text, we do not see any apparent tailoring between the text of the ads and the targeting attribute used.

4) Takeaways: A surprisingly large number of advertisers change the content of their ads either across users, across targeting attributes, or across time. While this practice is not entirely unexpected, that fact that it is very common amongst advertisers in the News and Politics category is unsettling, and emphasizes the need for auditing mechanisms that look at how advertisers are changing the content of their ads and how these changes impact users.

\section{RELATED WORK}

In this section we review studies that are the closest to our research; for a more general description of the landscape of digital advertising we refer the reader to Chen et al. [26], and for a general overview of privacy threats and protection approaches in targeted advertising to Jiménez et al. [29].

Studies of online ads: There are only a few studies, to our knowledge, that looked at ad related data of real-world Facebook users. The closest to our work is the study of Ribeiro et al. [37] who analyzed 3,517 political ads on Facebook that are linked to a Russian propaganda group: Internet Research Agency (IRA) and were released by the Democrats Permanent Select Committee on Intelligence in 2018. The study explores the extent to which one can exploit the Facebook targeted advertising infrastructure to target ads on divisive and polarizing topics. In contrast, our study analyzes ads at a much larger scale and focuses on how advertisers in general are targeting their ads. Cabañas et al. [24] analyzed $126 \mathrm{~K}$ interests from the Ads Preferences pages of more than $6 \mathrm{~K}$ users and used the Facebook Ads API to show that Facebook has inferred sensitive interests for $73 \%$ of EU users. This study is complementary to ours as it focuses on what information Facebook has inferred about users while we focus on how advertisers are actually using this information to target users.

A number of studies have looked at online ads in general and tried to understand and quantify how many are locationbased, contextual or behavioral [25], [35], [36], [42] and which factors/user actions have an effect on the ads users receive [23], [27], [30], [33], [34], [36]. The general methodology behind such studies is to create fake personas (by using a clean slate browser that visits certain specific sites) and then study the ads that are delivered to these personas. The only exception is the work of Parra-Arnau et al. [36] that performed a small-scale study of web ads received by 40 real-world users and observed that behavioral ads are more predominant on careers, education, news and politics categories. In contrast, our study focuses on ads on Facebook, and our data allows us to investigate advertiser strategies at a finer grain (e.g., looking at specific attributes used for targeting).

Studies of ad transparency mechanisms: Advertising platforms have started to provide users with privacy controls and transparency mechanisms where they show users what data they inferred about them or why they received a particular ad. Several studies have pointed problems with current implementations of such mechanisms [22], [27], [39], [42]. The aforementioned works of Wills et al. [42] and Datta et al. [27] suggested that the information provided in the Google Ad Settings page might not be complete as they found cases of targeted ads related to information that was not shown in the respective Ad Settings. Andreou et al. [22] showed through controlled experiments that the explanations provided by Facebook from the Ad Preferences page and the "Why am I seeing this?" button are often incomplete and sometimes misleading. Finally, a few studies investigated the impact of transparency mechanisms and privacy controls on the behavior of users: Tucker [39] showed that after the introduction of privacy controls in Facebook, users were twice as likely to click on personalized ads, and Eslami et al. [28] uncovered that users prefer interpretable non-creepy explanations. Our study exploits information provided in the "Why am I seeing this?" button to further identify advertisers' targeting practices that could potentially cause concern and, hence, require new auditing mechanisms.

Vulnerabilities of advertising interfaces: A few studies demonstrated how the Facebook advertising interface can be exploited by malicious advertisers to violate the security or privacy of users. Speicher et al. [38] showed that an illintentioned advertiser can exploit the targeting options provided by Facebook to send discriminatory advertising by targeting users based on their gender or race. Venkatadri et al. [41] found that the user's phone numbers which were given to Facebook for security purposes could be utilized by the advertisers to target users. In addition, Venkatadri et al. [40] demonstrated several attacks that allow adversaries to infer users' phone numbers or de-anonymize the visitors of a proprietary website. Finally, Korolova et al. [31] demonstrated mechanisms through which an advertiser can infer the private attributes of a user. In our study we just exploited the Facebook advertising interface to gather various statistics about the attributes Facebook allows advertisers to target users.

\section{CONCLUSION}

Online social network advertising is now a multi-billiondollar business. In this study, we shed some light into the advertising ecosystem on one of the largest of such platforms (Facebook) by collecting and analyzing data on the ads received by more than 600 real-world users. We looked into Who are the advertisers? as well as How are they using the platform? Our analysis revealed the frequency of potentially invasive and opaque targeting mechanisms (e.g., PII-based and Lookalike audiences), as well as mechanisms that have proven problematic in the recent past (e.g., free-text attributes). Moreover, we demonstrated the existence of advertisers who use a plethora of attributes to target users; who change the content of their ads across time, users, and targeting attributes; 
and who persistently target users across time. While our findings do not directly speak to malicious activity, privacy leaks, or discrimination, they raise questions that subsequent research in auditing these platforms should focus on.

\section{ACKNOWLEDGEMENTS}

We thank the anonymous reviewers and the shepherd for their helpful comments and assistance. This research was supported in part by NSF through grant CNS-1616234, by the French National Research Agency (ANR) through the Investissements davenir program (ANR-15-IDEX-02) and through grants ANR-17-CE23-0014 and ANR-16-TERC-0012, by the Alexander von Humboldt Foundation, by Institut Mines Telecom through the "Future \& Ruptures" program and by the Data Transparency Lab. F. Benvenuto acknowledges grants from $\mathrm{CNPq}$, and Fapemig.

\section{REFERENCES}

[1] "About lookalike audiences," https://www.facebook.com/business/help/ 164749007013531 accessed: 2018-12-14.

[2] “Acxiom," http://www.acxiom.com/ accessed: 2018-12-14.

[3] "Ad preferences," https://www.facebook.com/adsmanager/creation accessed: 2018-12-14.

[4] "Adanalyst," https://adanalyst.mpi-sws.org accessed: 2018-12-14.

[5] "The definitive list of what everyone likes on facebook," https://www.theverge.com/2016/2/1/10872792/facebook-interestsranked-preferred-audience-size accessed: 2018-12-14.

[6] "Epsilon," https://epsilon.com// accessed: 2018-12-14.

[7] "Experian," https://www.experian.com// accessed: 2018-12-14

[8] "Facebook ads," https://www.facebook.com/business/products/ads accessed: 2018-12-14.

[9] "Facebook enabled advertisers to reach jew haters," https://www.propublica.org/article/facebook-enabled-advertisersto-reach-jew-haters accessed: 2018-12-14.

[10] "Facebook plans crackdown on ad targeting by email without consent," https://techcrunch.com/2018/03/31/custom-audiences-certification accessed: 2018-12-14.

[11] "General data protection regulation," https://gdpr-info.eu/, accessed: 2018-12-14.

[12] "Google translate-detect language," https://cloud.google.com/translate/ docs/detecting-language accessed: 2018-12-14.

[13] "Honest ads," https://cbsn.ws/2Lsl1QK accessed: 2018-12-14.

[14] "How does facebook detailed targeting work?" https: //www.facebook.com/business/help/182371508761821 accessed: 2018-12-14.

[15] "Interactive advertising bureau (iab)," https://www.iab.com// accessed: 2018-12-14.

[16] "Is it age discrimination if you don't know youre being discriminated against?" https://www.propublica.org/article/is-it-age-discriminationif-you-dont-know-youre-being-discriminated-against accessed: 2018$12-14$.

[17] "Leveling the platform: Real transparency for paid messages on facebook," https://www.teamupturn.org/reports/2018/facebook-ads/ accessed: 2018-12-14.

[18] "Oracle data cloud," https://cloud.oracle.com/data-cloud accessed: 2018-12-14.

[19] "These are the ads russia bought on facebook in 2016," https://www.nytimes.com/2017/11/01/us/politics/russia-2016-electionfacebook.html accessed: 2018-12-14.

[20] "What are facebook's partner categories," https://web.archive.org/ web/20180930012557/https://www.facebook.com/business/help/ 298717656925097 accessed: 2018-12-14.

[21] "What is a verified page or profile?" https://www.facebook.com/help/ 196050490547892 accessed: 2018-12-14.
[22] A. Andreou, G. Venkatadri, O. Goga, K. P. Gummadi, P. Loiseau, and A. Mislove, "Investigating ad transparency mechanisms in social media: A case study of facebooks explanations," in NDSS, 2018.

[23] P. Barford, I. Canadi, D. Krushevskaja, Q. Ma, and S. Muthukrishnan, "Adscape: Harvesting and analyzing online display ads," in $W W W$, 2014.

[24] J. G. Cabañas, Á. Cuevas, and R. Cuevas, "Unveiling and quantifying facebook exploitation of sensitive personal data for advertising purposes," in USENIX Security, 2018.

[25] J. M. Carrascosa, J. Mikians, R. Cuevas, V. Erramilli, and N. Laoutaris, "I always feel like somebody's watching me: measuring online behavioural advertising," in ACM CoNEXT, 2015.

[26] G. Chen, J. H. Cox, A. S. Uluagac, and J. A. Copeland, "In-depth survey of digital advertising technologies," IEEE Communications Surveys \& Tutorials, vol. 18, no. 3, pp. 2124-2148, 2016.

[27] A. Datta, M. C. Tschantz, and A. Datta, "Automated experiments on ad privacy settings," in PETS, 2015.

[28] M. Eslami, S. R. Krishna Kumaran, C. Sandvig, and K. Karahalios, "Communicating algorithmic process in online behavioral advertising," in ACM CHI, 2018.

[29] J. Estrada-Jiménez, J. Parra-Arnau, A. Rodríguez-Hoyos, and J. Forné, "Online advertising: Analysis of privacy threats and protection approaches," Computer Communications, vol. 100, pp. 32-51, 2017.

[30] S. Guha, B. Cheng, and P. Francis, "Challenges in measuring online advertising systems," in ACM IMC, 2010.

[31] A. Korolova, "Privacy violations using microtargeted ads: A case study," in IEEE ICDMW, 2010.

[32] K. Krippendorff, "Computing krippendorff's alpha-reliability," 2011.

[33] M. Lécuyer, G. Ducoffe, F. Lan, A. Papancea, T. Petsios, R. Spahn, A. Chaintreau, and R. Geambasu, "Xray: Enhancing the web's transparency with differential correlation." in USENIX Security, 2014.

[34] M. Lecuyer, R. Spahn, Y. Spiliopolous, A. Chaintreau, R. Geambasu, and D. Hsu, "Sunlight: Fine-grained targeting detection at scale with statistical confidence," in ACM CCS, 2015.

[35] B. Liu, A. Sheth, U. Weinsberg, J. Chandrashekar, and R. Govindan, "Adreveal: improving transparency into online targeted advertising," in ACM HotNets, 2013.

[36] J. Parra-Arnau, J. P. Achara, and C. Castelluccia, "Myadchoices: Bringing transparency and control to online advertising," ACM TWEB, vol. 11 , no. $1,2017$.

[37] F. N. Ribeiro, K. Saha, M. Babaei, L. Henrique, J. Messias, O. Goga, F. Benevenuto, K. P. Gummadi, and E. M. Redmiles, "On microtargeting socially divisive ads: A case study of russia-linked ad campaigns on facebook," in $A C M F A T^{*}, 2019$.

[38] T. Speicher, M. Ali, G. Venkatadri, F. N. Ribeiro, G. Arvanitakis, F. Benevenuto, K. P. Gummadi, P. Loiseau, and A. Mislove, "Potential for discrimination in online targeted advertising," in $A C M F A T^{*}, 2018$.

[39] C. E. Tucker, "Social networks, personalized advertising, and privacy controls," Journal of Marketing Research, vol. 51, no. 5, pp. 546-562, 2014.

[40] G. Venkatadri, A. Andreou, Y. Liu, A. Mislove, K. P. Gummadi, P. Loiseau, and O. Goga, "Privacy risks with Facebook's PII-based targeting: Auditing a data broker's advertising interface," in IEEE $S \& P$, 2018.

[41] G. Venkatadri, E. Lucherini, P. Sapiezyski, and A. Mislove, "Investigating sources of PII used in Facebook's targeted advertising," in PETS, 2019.

[42] C. E. Wills and C. Tatar, "Understanding what they do with what they know," in ACM WPES, 2012 